\title{
Comparison of Apical Leakage in Root Canal Obturation Using Bioceramic and Polydimethylsiloxane Sealer (In Vitro)
}

\author{
Bina Amanda ${ }^{1}$, Endang Suprastiwi ${ }^{2}$, Munyati Usman ${ }^{2 *}$ \\ ${ }^{1}$ Resident of Department of Conservative Dentistry, Faculty of Dentistry, Universitas Indonesia, Jakarta, Indonesia \\ ${ }^{2}$ Departement of Conservative Dentistry, Faculty of Dentistry, Universitas Indonesia, Jakarta, Indonesia \\ Email: *esuprastiwi@google.com
}

How to cite this paper: Amanda, B., Suprastiwi, E. and Usman, M. (2018) Comparison of Apical Leakage in Root Canal Obturation Using Bioceramic and Polydimethylsiloxane Sealer (In Vitro). Open Journal of Stomatology, 8, 24-34. https://doi.org/10.4236/ojst.2018.81003

Received: December 4, 2017

Accepted: January 16, 2018

Published: January 19, 2018

Copyright $\odot 2018$ by authors and Scientific Research Publishing Inc. This work is licensed under the Creative Commons Attribution International License (CC BY 4.0).

http://creativecommons.org/licenses/by/4.0/

\begin{abstract}
Background: One of the ideal properties of a root canal sealer is to have a good sealing ability, especially at the apical third of the root. Objective: To evaluate the comparison of the apical leakage between obturation using bioceramic sealer (BS) and polydimethylsiloxane sealer (PS). Materials and Methods: Thirty-six mandibular premolars were equally divided into two groups and were obturated with single cone technique. The sealers used for Group I and Group II were BS and PS respectively. After obturation, the samples were incubated $\left(37^{\circ} \mathrm{C}, 24 \mathrm{~h}\right)$, sealed with two coats of nail polish except for $2 \mathrm{~mm}$ from the apex, submerged in the Indian ink for 7 days, decalcified, dehydrated, and made transparent according to Robertson technique. Dye penetration was evaluated under stereomicroscope. Samples without dye penetration were given score 0 , dye penetration $\leq 0.5 \mathrm{~mm}$ were given score $1,0.51-1$ $\mathrm{mm}$ were given score 2 , and $>1 \mathrm{~mm}$ were given score 3 . Result: The largest proportion distribution in BS group was at the score 1 (55.6\%), whereas in PS group was at the score 2 (44.4\%). Conclusion: Bioceramic sealer showed similar apical leakage to polydimethylsiloxane sealer. Clinical Relevance: Based on this study, bioceramic sealer can be recommended to be used as sealer with low level of apical leakage as well as polydimethylsiloxane sealer.
\end{abstract}

\section{Keywords}

Bioceramic Sealer, Polydimethylsiloxane Sealer, Apical Leakage

\section{Introduction}

The success of a root canal treatment depends on the debridement, elimination 
of pathological organisms, and exceptional sealing at the root canal to prevent penetration or re-entering of pathological microorganism back into the root canal and periradicular tissue [1]. Every single step of a root canal treatment has its own important role, however obturation or the filling of the root canal is the key factor in obtaining success in a root canal treatment [2].

The main goal in root canal obturation is to seal the communication between periapical, periodontal space, and the root canal, thus locking and suppressing the remaining microorganism in the root canal and preventing re-infection. A study by Ingle et al. (2002) about the success of root canal treatment indicated that $58 \%$ of unsuccessful root canal treatment occurred because of poor obturation [3]. A study conducted on 1001 teeth that had gone through endodontic treatments also showed that inadequate obturation was the reason for unsuccessful treatment [4].

The gold standard material for canal space obturation is the gutta-percha cone with sealer. Gutta-percha does not bond with the wall of the root canal; hence the use of sealer with good adapted gutta-percha is essential in obtaining adequate endodontic treatment result [2]. Gutta-percha is a rigid material that will undergo shrinkage and create space that can be used as an access way for bacteria. Thus root canal sealer is vital to fill in the space [5]. Sealer applied in the canal space will fill in the imperfections and increase the adaptability of the filler to the root canal wall [6].

Ideally, root canal sealer has to be biocompatible, anti bacteria, non-toxic to the body tissue, insoluble in body tissue fluid, radiopaque, easy to use, stable, has a good adhesion, and was able to eliminate surface area between gutta-percha and canal wall [7]. Root canal filling material must be able to forge a barrier that can prevent bacteria entering the root canal space by creating monoblock bonding. The concept of monoblock bonding is to create genuine gap-free solid filling mass that would form a real fluid-tight seal. However, it is proven difficult clinically to create a monoblock bonding in the root canal obturation. Sealer acts as the essential material to form bonding with the root canal wall in order to create the monoblock condition [5].

According to Tronstad et al. (2000), tight sealing of the canal space is necessary to maintain satisfactory condition of the periapical tissue [8] [9]. Therefore, the physical properties that need to be observed from a root canal sealer is its ability to adhere with the root canal wall and gutta-percha, the solubility against the body tissue fluid, and its stability after hardened. For those purposes, several new sealers had been developed to gain these properties in order to produce the best sealer [5].

Recently, the adhesive obturation system was being introduced in endodontic treatment in order to achieve the monoblock concept, meaning that the core material, sealing agent, and dentin at root canal would form a single cohesive bonding inside the canal space. The increase of the adhesive bonding between the core material, sealer and canal wall will also strengthen the tooth thus making it resistant against fracture and extend the clinical age of the tooth after en- 
dodontic treatment [10].

Bioceramic and polydimethylsiloxane are sealer materials that are currently used and developed [10]. Both sealers have good biocompability characteristics against the body tissue, low solubility, and good flow. Bioceramic sealer is able to diffuse into dentinal tubules to create mechanical interlocking bonds and form a hydroxyapatite-like structure along the mineral infiltration zone [9]. Meanwhile polydimethylsiloxane sealer is able to expand as much as $0.2 \%$ after hardened thus making it able to fill the spaces formed by the irregularity of the canal wall. Of all the various properties mentioned above, it can be concluded that both sealers have exceptional root canal sealing ability [5] [9].

A research conducted by Akcay et al. (2016) using a confocal microscope showed that bioceramic sealer (iRootSP) had the highest penetration level into the dentinal tubules compared to epoxy resin based sealer (AH Plus), MTA sealer (MTA Fillapex), and third generation polydimethylsiloxane sealer which is GuttaFlow Bioseal. In that research, the irrigation technic was also studied [11]. The result of this research is similar to a research conducted by Herfiana (2011) which showed that the sealing ability of bioceramic sealer (Endosequence BC) is better than resin based sealer (AH Plus) [12]. However, a research by Xue et al. (2014) showed that the sealing ability at the apical third of the root between bioceramic sealer (iRootSP) and resin-based (AH Plus) statistically had no significant differences and both has good abilities [13].

A research by Pratiwi (2013) showed that microleakage in obturation using polydimethylsiloxane sealer at the apical third of the root is lower when compared to epoxy resin-based sealer (AH Plus) [14]. A research conducted by Ebert et al. (2014) also showed that the next generation of polydimethylsiloxane sealer, which is GuttaFlow 2, had lower dye penetration leakage compared to GuttaFlow and AH Plus [15]. But a research conducted by Sonu et al. (2016), showed a different result, polydimethylsiloxane sealer (GuttaFlow 2) had minimum penetration ability into the dentinal tubules compared to resins based sealer ( $\mathrm{AH}$ Plus) [16]. Naser (2015) also stated that the use of GuttaFlow 2 with single cone obturation technic was equivalent to the use of AH Plus sealer with single cone obturation technic [17].

Even with studies that showed various results, there are still no studies that compare the leakage between bioceramic sealer and polydimethylsiloxane sealer at apical third of the root in order to determine which obturation material has the best sealing ability and therefore the main objective of root canal treatment may be achieved.

\section{Research Method}

This research is a laboratory experimental research. It was conducted at Dental Conservative Specialist Clinic, Faculty of Dentistry, Universitas Indonesia and also at Biomedical Technology Laboratory, Universitas Indonesia. This study has done in August-November 2016. 
Thirty-six mandibular premolars were cleaned using scaler and then were submerged inside $\mathrm{NaCl} 0.9 \%$ solution until the preparation and obturation of the root canal. The samples then were randomly selected and divided into two groups, the BS (Bioceramic Sealer) and PS (Polydimethylsiloxane Sealer) groups. Both groups were prepared using the crown down technic with Protaper Next rotary instrument until X3. Final working length was set at $\pm 1 \mathrm{~mm}$ from apical foramen.

EDTA gel 17\% was used as lubricants during root canal preparation and instrument changing; and as irrigant, $1 \mathrm{ml}$ of $\mathrm{NaOCl} 2.5 \%$ was used every instrument changing. Once the root canal preparation is completed, all canal space was irrigated using EDTA liquid $17 \%$, set aside for 1 minute and then rinsed with $\mathrm{NaOCl} 2.5 \%$.

The prepared and irrigated root canals were then dried using paper point, then the GuttaFlow sealer (PS group) and bioceramic sealer (BS group) were applied into the canal space using provided syringes. The master gutta-percha cone (Protaper Next) was then coated in sealer and inserted into the canal space all the way to the final working length. Overflowed sealer was then cleaned and the excess of gutta-percha cone was cut using hot instrument. After the obturation is done, the density of all research samples was evaluated using radiographic photo in accordance to the inclusion criteria. The crown section was given SIKMR base. All samples were incubated for 24 hours on temperature of $37^{\circ} \mathrm{C}$ and $100 \%$ humidity until sealer is harden.

Samples were then air-dried and the outer part of the root was coated with two layers of nail polish except at the $2 \mathrm{~mm}$ from the apex. The first layer was set aside to dry on the temperature of $37^{\circ} \mathrm{C}$ for 1 hour before the second layer was applied in the same way as the first layer.

After 1 hour, all samples were submerged in Indian ink for $7 \times 24$ hours on the temperature of $37^{\circ} \mathrm{C}$. After all samples were taken out of the ink solution, they were rinsed under running water and the nail polish was scraped off using scalpel. The next phase was decalcification process and samples were made transparent in accordance to Robertson method. First step was decalcifying samples by submerging the samples into the nitric acid $5 \%$ for $3 \times 24$ hours. The acid solution was changed everyday, shaken three times daily and on the third day the samples were examined by thrusting a needle through the crown section. If the needle went through, the sample is soft enough and ready for the next phase.

The samples were then rinsed under running water for four hours. The next phase was dehydration by submerging the samples inside $70 \%$ alcohol for 12 hours, $80 \%$ alcohol for 12 hours, $90 \%$ alcohol for 6 hours, and finally $100 \%$ alcohol for 3 hours; the alcohol solution was changed every hour.

The final phase was transparency by submerging the samples inside salicylic acid $100 \%$ for 2 hours on the temperature of $37^{\circ} \mathrm{C}$ that would make the samples transparent. After all specimens were transparent, the root canal filling was evaluated and all samples were ready to be studied. 
Observation procedure was done using a stereomicroscope (Discovery V12, Carl Zeiss, AxioCam, Germany) with twenty times magnification. The collected data includes the leakage of dye along the canal space and how deep the dye penetration is on each sample, measured in millimeter grid confirmed with Zen software, 2011. Dye penetration leakage scoring were (a) score 0-no leakage, (b) score 1 -leakage $\leq 0.5 \mathrm{~mm}$; (c) score 2-leakage $0.51-1 \mathrm{~mm}$, and (d) score 3-leakage $>1 \mathrm{~mm}$.

Dye penetration data was analyzed with parametrical statistical test using SPSS 20 software. Statistical analysis was done using Chi-square parametrical test to verify the significance level on all groups with the significance level of $\mathrm{p}<$ 0.05 .

\section{Result}

The scoring results for the observed sample shown in Figure 1. The penetration of the dye range from 0 until more than $1 \mathrm{~mm}$ from the apex.

Based on observation on all samples, the leakage scoring can be seen on Table 1.

Based on Table 1, the highest distribution of leakage scoring on polydimethylsiloxane sealer group is shown on score 2, which is $44.4 \%$, while on the bioceramic sealer is on score 1 , which is $55.6 \%$. Both groups have samples that showed no leakage. There are 2 samples $(11.1 \%)$ on the polydimethylsiloxane

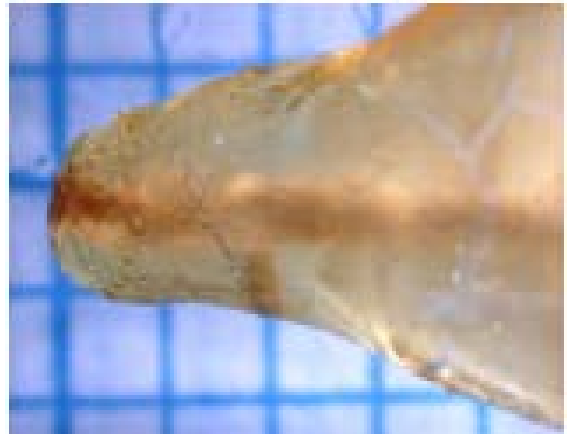

(a)

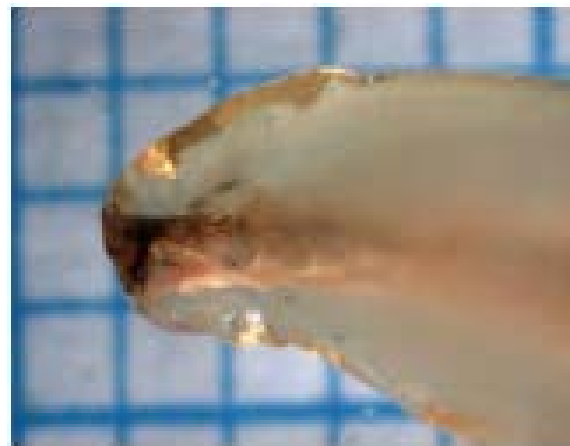

(c)

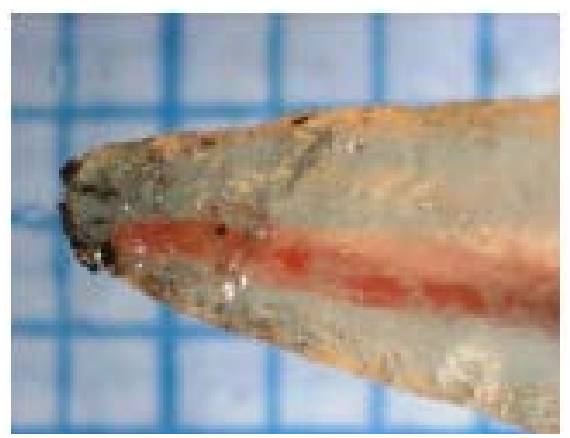

(b)

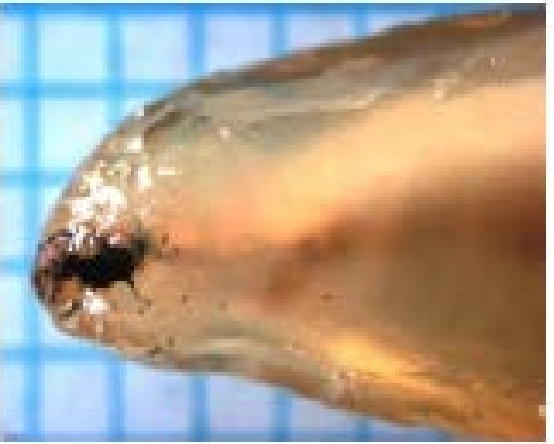

(d)

Figure 1. Dye penetration leakage. (a) score 0 -no leakage; (b) score 1 -leakage $\leq 0.5$ $\mathrm{mm}$; (c) score 2-leakage $0.51-1 \mathrm{~mm}$; (d) score 3-leakage $>1 \mathrm{~mm}$. 
Table 1. Microleakage scoring distribution between Bioceramic Sealer and Polydimethylsiloxane Sealer.

\begin{tabular}{|c|c|c|c|c|c|}
\hline \multirow{2}{*}{ Test Groups } & \multicolumn{4}{|c|}{ Leakage scoring } & \multirow[t]{2}{*}{$p$-value } \\
\hline & 0 & 1 & 2 & 3 & \\
\hline $\begin{array}{l}\text { Bioceramic Sealer } \\
(\mathrm{n}=18)\end{array}$ & $4(22.2 \%)$ & $10(55.6 \%)$ & $3(16.7 \%)$ & $1(5.6 \%)$ & 0.063 \\
\hline $\begin{array}{l}\text { Polydimethylsiloxane Sealer } \\
\qquad(\mathrm{n}=18)\end{array}$ & $2(11.1 \%)$ & $6(33.3 \%)$ & $8(44.4 \%)$ & $2(11.1 \%)$ & \\
\hline
\end{tabular}

sealer group and 4 samples $(22.2 \%)$ on bioceramic sealer group that showed no leakage.

Based on Mann-Whitney significance test, the significance level between two groups are $>0.05$, which is 0.063 . The conclusion that can be made based on table 1 was that statistically there is no significant difference of leakage between the bioceramic sealer group and polydimethylsiloxane sealer group.

\section{Discussion}

Root canal sealer is used to fill gaps between gutta-percha and dentinal wall hence creating coherent mass of filler and fluid tight seal. This study is done to observe the differences of the sealing ability of bioceramic sealer (BS) and polydimethylsiloxane sealer (PS). Sealing ability on the root canal was scored by observing the level of coloring dye leakage on apical third of the root. The apical third of the root is a very complex section, harder to clean, has a vast anatomy variation such as ramifications, lateral canal, or accessory canals that made it susceptible to leaking [18].

The amount of samples used for this research is 36 teeth with 18 samples in each group according to calculation by G. Power software v3.1.9.2.

The sealing ability of a sealer is determined by the connection or bonding between sealer and dentin, and also by the physical properties of the sealer itself. Less than optimal removal of smear layer will interfere the bonding between sealer and dentin. Preparation of the root canal on this study was done using crown down technic since it has some advantages, i.e. minimalizing debris extrusion to the apex, optimizing cleaning and shaping process of the canal space, and maximizing the volume and deeper penetration of the irrigant [16].

Irrigant used for this study is a combination of $\mathrm{NaOCl} 2.5 \%$ and EDTA $17 \%$. $\mathrm{NaOCl} 2.5 \%$ has the ability to dissolve pulp tissue and is an excellent antimicrobial agent that can eliminate pathogenic bacteria such as gram negative bacteria, fungi, spores, and viruses. EDTA $17 \%$ was used to dissolve anorganic tissue and smear layer. EDTA gel was also used on this study as lubricants and to dissolve calcification in the canal space. Aside from the irrigants, the irrigation technic also holds an important role in creating the sealing ability of obturation material. Irrigant activation with the sonic technic is proven to be able to remove smear layer more effectively compared to the manual agitation technic [16].

The obturation of the canal space in this study was done with single cone 
technic. It is technically easier and faster. The quality of root canal filling with single cone technic had been evaluated by a lot of researchers. According to one study by Yulianda (2015), single cone technic with polydimethylsiloxane sealer would create more dense obturation when compared to downpack-backfill technic, although statistically there is no significant differences [19]. Wu et al. compared the obturation in a curved canal space using single cone technic and lateral condensation with AH Plus sealer, and concluded that the sealing ability of single cone technic is the same as lateral condensation technic [20].

This study used bioceramic sealer as well as polydimethylsiloxane sealer. Physical properties of both these sealers are adequate to meet the ideal requirements of root canal space sealer as stated by Grossman, which are biocompatible, anti bacterial, non-toxic to the body tissue, insoluble in tissue fluid, radiopaque, easy to use, stable, and has good adhesion. With those physical properties, both of these sealers are considered superior compared to the other base sealers, including the resin-based sealer which is the gold standard material of root canal sealer [2] [5]. This study correlates to a study conducted by Herfiana (2011), where bioceramic sealer has better sealing ability when compared to the resin-based sealer with cold carrier thermoplastic filling method [12]. A study by Pratiwi (2012) showed that the microleakage which occurred on the apical third of the root after the obturation of the canal space with new generation of polydimethylsiloxane sealer is lower when compared to epoxy resin sealer. From both these studies, the chance of leakage on obturation using epoxy resin sealer occured due to the basic properties of resin which is shrinkage during polymerization process, where this would eventually create gap in the obturation and cause leakage of the root canal obturation [14].

Polydimethylsiloxane sealer property is cold flowable and does not require increase in temperature such as in thermoplastic material. According to study by Yulianda (2015), single cone technic would provide better density compared to the downpack-backfill technic, although statistically there is no significant differences between both technics. From that study, when heat was applied, polydimethylsiloxane sealer that consists of nano particle of gutta-percha would expand larger than its expansion ability and then underwent shrinkage thus creating gaps in the root canal obturation. That study used coloring dye penetration technic by performing decalcification, dehydration, and making the samples transparent beforehand [19] [21].

For the bioceramic filler, Hedge and Arora (2015) showed that obturating the root canal space with a combination of single cone with bioceramic sealer has better sealing ability compared to lateral condensation technic using the glucose leakage model technic. Koch dan Brave (2012) stated that the obturation technic using bioceramic sealer could also be called the synchronized hydraulic condensation techinc. This technic consists of inserting the sealer into the canal space that is not deeper than the coronal one third, using provided capillary tip that would be able to distribute fine size particles, which is $\leq 2 \mu \mathrm{m}$. After that, it pro- 
ceed to coat the master cone with sealer and slowly insert it into the canal all the way to the final working length that would then create excellent hydraulic of the sealer, distributing it in all directions and form excellent sealing. This technic is similar to the single cone technic [22].

To assess the leakage at the apical one third of the root, this study uses coloring dye penetration that can be seen after samples were decalcified, dehydrated, and made transparent using Robertson method. This method is capable to give three-dimensional anatomy illustration of the internal canal space without eliminating the substance of the tooth thus making it easier to make assessment of the leakage. This technic could also show the anatomical variation of the canal such as lateral and accessory canals and is better in detecting leakage at the apical third of the root compared to transversal cutting technic because it is able to give leakage visualization at the apex in millimeter dimensions, as for the transversal technic the leakage level cannot be determined [21].

On the distribution table of leakage at the apical third of the root, the highest scoring for the polydimethylsiloxane sealer is on score 2 , which is $44.4 \%$, while for the bioceramic sealer is on score 1 , which is $55.6 \%$. On both groups, there are samples that showed no leakage, with two samples on polydimethylsiloxane sealer group, and four samples on the BS group (Table 1). This showed that both these sealers have excellent sealing ability. However, from Mann-Whitney significance test, there are no significant differences found from these two groups ( $p$ $=0.063)$. Therefore, the hypothesis of this study that bioceramic sealer has lower microleakage compared to polydimethylsiloxane sealer, when used as filling of the canal, is overthrown since it cannot be statistically proven.

The ability to achieve excellent sealing on bioceramic sealer and polydimethylsiloxane sealer can be obtained due to their physical properties that are almost ideal as the sealer for the canal space, i.e. the sealer must be stable, display no shrinkage after harden, and not easily dissolved. Other possibility would be the ability of bioceramic sealer and polydimethylsiloxane sealer to create monoblock concept, which is a concept to create a genuine gap-free solid filling mass that would form a real fluid-tight seal condition. This monoblock concept was obtained from the way the sealer bond with the dentinal wall of the canal space. These sealers have different bonding mechanism with the dentin. Bioceramic sealer is able to bond chemically and mechanically, while the polydimethylsiloxane sealer bonds physically and mechanically with the dentinal wall of the canal space.

The chemical hardening reaction of the bioceramic sealer would create a layer with hydroxyapatite-like structure. Aside from that, the flow of this sealer is quite good that made it able to penetrate into lateral and accessory canals, and even into the dentinal tubules. Bioceramic sealer also consists of fine size particles, with the size of $1.4 \mu \mathrm{m}$ which made it possible to penetrate into the dentinal tubules with diameter of $2.5 \mu \mathrm{m}$ at the canal space thus forming a micromechanical bond [1]. 
Polydimethylsiloxane sealer consists of fine powder particles of gutta-percha that is added to silicone-based sealer (Roeko Seal). The size of the gutta-percha in the GuttaFlow is very small, less than $30 \mu \mathrm{m}$ [23] [24]. Physically, this sealer is similar to the base material, which is gutta-percha, which would make it easy for this sealer to achieve monoblock concept with the base material. From this study, it can be concluded that this material can fill the irregularity of canal space. GuttaFlow 2 is also thixotrophic, meaning that the viscosity will lessen if pressurized. Therefore, pressure from gutta-percha cone, along with the fine particle size of the GuttaFlow 2 filler would make it able to penetrate into the dentinal tubules and into very small lateral or accessory canals. The hardening ability is also very good because GuttaFlow would expand only slightly when harden, which is $0.2 \%$ [2] [23] [24].

\section{Conclusions}

From this study, it can be concluded that the microleakage level at canal space using bioceramic sealer has no difference when compared to polydimethylsiloxane sealer.

Further research must be done with more samples, to determine the significant level of microleakage from both sealers. Standard operating procedures of decalcification, dehydration, and making the samples transparent to observe coloring dye penetration also need to be determined to minimize the penetration bias caused by incorrect decalcification procedure. An SEM testing is also needed to see the ability of the sealer to penetrate into dentinal tubules.

\section{Compliance with Ethical Standards}

\section{Conflict of Interest}

All authors declare no conflict of interest in this study.

\section{Funding}

This study was supported by Universitas Indonesia and Publikasi Terindeks Internasional Untuk Tugas Akhir Mahasiswa (PITTA) Universitas Indonesia.

\section{Ethical Approval}

This article does not contain any studies with human participants or animals performed by any of the authors.

\section{References}

[1] Razmi, H., Bolhari, B., Dashti, N.K. and Fazlyab, M. (2016) The Effect of Canal Dryness on Bond Strength of Bioceramic and Epoxy-Resin Sealers after Irrigation with Sodium. Iranian Endodontic Journal, 11, 129-133.

[2] Setia, P., Sikri, V.K., Sroa, R.B. and Sidhu, B. (2013) Apical Sealing Ability of Two Novel Root Canal Sealers: An ex-vivo Study. Journal of the International Clinical Dental Research Organization, 5, 9-13.

[3] Pawar, S., Pujar, M. and Makandar, S. (2014) Evaluation of the Apical Sealing Abil- 
ity of Bioceramic Sealer, AH Plus \& Epiphany: An in vitro Study. Journal of Conservative Dentistry, 17, 579-582. https://doi.org/10.4103/0972-0707.144609

[4] Tabassum, S. and Khan, F.R. (2016) Failure of Endodontic Treatment: The Usual Suspects. European Journal of Dentistry, 10, 144-147.

https://doi.org/10.4103/1305-7456.175682

[5] Singh, H., Markan, S., Kaur, M. and Gupta, G. (2015) Endodontic Sealers' Current Concepts and Comparative Analysis. The Open Dentistry Journal, 2, 32-37. https://doi.org/10.17140/DOJ-2-107

[6] Baechtold, M., Leonardi, D., Tomazinho, F., Scaini, F., Barato-Filho, F. and Haragushiku, G. (2015) Bacterial Leakage of Mineral Trioxide Aggregate-Based and Resin-Based Sealers in Teeth Ready for Root Retainers. Journal of Dental Applications, 2, 214-218.

[7] Wang, Z. (2015) Bioceramic Material in Endodontics. Endodontic Topics, 32, 3-30. https://doi.org/10.1111/etp.12075

[8] Gurgel-Georgelin, M. and Diemer, F. (2011) Sealer Penetration and Adaptation in the Dentinal Tubules: A Scanning Electron Microscopic Study. Journal of Endodontics, 37, 1576-1579. https://doi.org/10.1016/j.joen.2011.07.005

[9] Al-Haddad, A. and Aziz, Z.A.C.A. (2016) Bioceramic-Based Root Canal Sealers : A Review. International Journal of Biomaterials, 2016, 1-10. https://doi.org/10.1155/2016/9753210

[10] Bouillaguet, S., Shaw, L., Barthelemy, J., Krejci, I. and Wataha, J.C. (2008) Long-Term Sealing Ability of Pulp Canal Sealer, AH-Plus, GuttaFlow and Epiphany. International Endodontic Journal, 41, 219-226. https://doi.org/10.1111/j.1365-2591.2007.01343.x

[11] Akcay, M., Arslan, H., Durmus, N., Mese, M. and Capar, I.D. (2016) Dentinal Tubule Penetration of AH Plus, iRoot SP, MTA Fillapex, and Guttaflow Bioseal Root Canal Sealers after Different Final Irrigation Procedures: A Confocal Microscopic Study. Lasers in Surgery and Medicine, 48, 70-76. https://doi.org/10.1002/lsm.22446

[12] Herfiana, T. (2011) Perbedaan Kemampuan Penutupan antara Siler Saluran Akar Resin dan Kalsium Silikat. Universitas Indonesia, Jakarta.

[13] Ming, X., Fen, W., Jin-Ming, W. and Ning, Q. (2014) Study on Apical Sealing Ability of iRoot SP Root Canal Sealer with Single-Cone Obtruation Technique. Acta Metallurgica Sinica, 7, 32-35.

[14] Pratiwi, N.A. (2012) Perbandingan Kebocoran Mikro antara Pengisian Saluran Akar dengan Siler Resin Epoksi dan Polidimetilsiloksan Generasi Baru pada Sepertiga Apeks. Universitas Indonesia, Jakarta.

[15] Ebert, J., Holzschuh, B., Frankenberger, R., Petschelt, A. and Roggendorf, M.J. (2014) Sealing Ability of Different Versions of GuttaFlow2 in Comparison to GuttaFlow and AH Plus. Revista Sul-Brasileira de Odontologia, 11, 224-229.

[16] Sonu, K.R., Girish, T.N., Ponnappa, K.C., Kishan, K.V. and Thameem, P.K. (2016) "Comparative Evaluation of Dentinal Penetration of Three Different Endodontic Sealers with and without Smear Layer Removal"-Scanning Electron Microscopic Study. Saudi Endodontic Journal, 6, 16-20. https://doi.org/10.4103/1658-5984.171996

[17] Naser, S.H. (2015) The Sealing Ability of Guttaflow2 Sealer in Comparison to AH plus Sealer Using Dye Penetration Method. Journal of Alrafidain University College, No. 36, 337-347.

[18] Chaudhari, A., Asthana, G., Parmar, G., Vadher, R. and Kaur, M. (2014) Significant of Apical Third: A Review. Scholars Journal of Applied Medical Sciences, 2, 
1613-1617.

[19] Yulianda, S.S. (2016) Perbandingan Kerapatan Pengisian Saluran Akar di Sepertiga Apeks Antara Teknik Kon Tunggal dan Downpack-Backfill Menggunakan Siler Polidimetilsiloksan. Universitas Indonesia, Depok.

[20] Yoshikawa, M., Noguchi, K. and Toda, T. (1997) Effect of Particle Sizes in India Ink on Its Use in Evaluation of Apical Seal. Journal of Osaka Dental University, 31, 67-70.

[21] Mokhtari, H., et al. (2015) Evaluation of Apical Leakage in Root Canals Obturated with Three Different Sealers in Presence or Absence of Smear Layer. Iranian Endodontic Journal, 10, 131-134.

[22] Koch, K., Brave, D. and Nasseh, A.A. (2012) A Review of Bioceramic Technology in Endodontics. C.E. Article, 6-12.

[23] Rana, M., Sandhu, G.K., Kaur, T., Arif, M. and Galyan, G. (2014) Original Article New Self Curing Root Canal Filling Material: Gutta Flow 2. Journal of Advanced Medical and Dental Sciences Research, 2, 15-20.

[24] Silva, E.J.N.L., Herrera, D.R., Rosa, T.P., Duque, T.M., Gomes, B.P.F.A. and Zaia, A.A. (2014) Evaluation of Cytotoxicity and Physicochemical Properties of Silicone-Based Endodontic Sealer GuttaFlow 2. Endodontic Practice Today, 8, 57-62. 